\title{
Effectiveness of etilefrine regimen for chylothorax after esophagectomy with thoracic duct resection
}

\author{
Yu Ohkura ${ }^{1} \cdot$ Masaki Ueno $^{1} \cdot$ Toshiro Iizuka $^{2} \cdot$ Harushi Udagawa $^{1}$
}

Received: 24 June 2017 / Accepted: 6 September 2017 / Published online: 14 September 2017

(C) The Author(s) 2017. This article is an open access publication

\begin{abstract}
Background Management of postoperative chylothorax generally involves nutritional regimens as well as pharmacological and surgical therapies, but a clear consensus has yet to be reached.

Methods Retrospective review of 371 patients who underwent esophagectomy for esophageal cancer was performed. They were patients with squamous cell carcinoma or adenocarcinoma of the esophagus including Siewert type I/II tumor of the esophagogastric junction who underwent subtotal esophagectomy. Of these patients, 19 patients who were diagnosed with chylothorax as a postoperative complication were enrolled in this study.

Results Conservative treatment achieved cure in 16 patients among 19 patients. The duration of chylothorax tended to be longer in the no-etilefrine group $(n=5)$ than in the etilefrine group ( $n=11$ ) (27.8 vs. 11.6 days; $p=0.078$ ). The 14 patients among 19 patients resected the thoracic duct. Etilefrine was used in 12 of these 14 patients. Among these 12 patients, 3 required surgical treatment and the remaining 9 patients were cured with conservative treatment. The duration of chylothorax was shorter in the conservative treatment group than in the surgical treatment group (11.9 vs. 36.3 days; $p=0.052$ ). In addition, with the use of etilefrine
\end{abstract}

Yu Ohkura

yu.ohkura107@gmail.com

1 Department of Gastroenterological Surgery, Toranomon Hospital, and Okinaka Memorial Institute for Medical Research, 2-2-2 Toranomon, Minato-ku, Tokyo 105-8470, Japan

2 Department of Gastroenterology, Toranomon Hospital, and Okinaka Memorial Institute for Medical Research, Tokyo, Japan as adjuvant therapy, cure was achieved in 9 patients (75\%) without surgical intervention.

Conclusions The findings of this study suggest that when used concurrently with conventional treatments, etilefrine facilitates early chest tube removal. In addition, post-thoracic duct resection chylothorax, which frequently requires surgical treatment because of the general less effectiveness of conservative treatments, showed high successful rate (75\%) to etilefrine treatment.

Keywords Chylothorax $\cdot$ Etilefrine $\cdot$ Octreotide $\cdot$ Pleural adhesion · Esophagectomy

\section{Abbreviation \\ TDR Thoracic duct resection}

\section{Introduction}

Postoperative chylothorax after esophagectomy occurs relatively infrequently, in about $2-9 \%$ of patients [1-3]. Management of postoperative chylothorax generally involves nutritional regimens as well as pharmacological and surgical therapies, but a clear consensus has yet to be reached [4]. Previous reports have noted the difficulty of using only medical management consisting of a nutritional regimen, etilefrine, octreotide, and picibanil (OK-432) for patients who have undergone thoracic duct resection, and that these therapies for chylothorax were indicated only for those patients in whom the thoracic duct was preserved [5-8]. However, if these therapies could be successful even in cases of thoracic duct resection, medical management alone would be advantageous because the patient would not need to undergo reoperation which might be associated with complications. 
In addition, it may be difficult to identify the site of leakage during surgery.

In this study, we investigated the usefulness of an etilefrine regimen to broaden the medical treatment options for postoperative chylothorax after esophagectomy with resection of the thoracic duct.

\section{Methods}

\section{Study population}

This single-center retrospective study was conducted to evaluate the effectiveness of therapy with an etilefrine regimen for chylothorax after esophagectomy. A total of 371 consecutive patients with esophageal cancer were identified from a prospectively constructed database at the Department of Gastroenterological Surgery, Toranomon Hospital between January 2011 and February 2017. They were patients with squamous cell carcinoma or adenocarcinoma of the esophagus including Siewert type I, II tumor of the esophagogastric junction who underwent subtotal esophagectomy. Of these 371 patients, 19 patients who were diagnosed with chylothorax as a postoperative complication were enrolled in this study. We investigated the clinical effectiveness of etilefrine for the management of postoperative chylothorax following esophagectomy particularly among patients with resection of the thoracic duct. Disease was staged according to the UICC TNM grading system, 7th edition [9]. We graded all postoperative complications based on the Clavien-Dindo classification [10], and grade $\geq 2$ events were documented as complications. This study was conducted with approval from the Institutional Review Board of Toranomon Hospital.

\section{Operative procedure for esophagectomy}

We perform esophagectomy with 2- or 3-field lymph node dissection depending on the degree of progression and surgical risk involved. The operative thoracic approach is by video-assisted thoracoscopic surgery or thoracotomy, and the abdominal approach is hand-assisted laparoscopic surgery or open laparotomy depending on individual cases. The thoracoscopic approach involves insertion of 5- or 12-mm ports through the second and fourth intercostal spaces on the anterior axillary line (assistant's ports) and 11-mm ports through the fifth intercostal space at the mid-axillary line (camera port) and in the fourth $(5 \mathrm{~mm})$ and sixth $(11 \mathrm{~mm})$ intercostal spaces on the posterior axillary line (operator's ports). We preserved the thoracic duct in cases with clinical stage (cStage) I and performed resection in cases with cStage $\geq$ II based on the UICC TNM grading system, 7th edition [9]. The reconstruction technique was either gastric tube reconstruction, or ileocolon reconstruction.

\section{Definition of chylothorax}

Chylothorax was suspected in the presence of excessive ( $>800 \mathrm{~mL} /$ day) chest drain output or if the color of chest drainage fluid turn milky white after tube feeding or oral ingestion. The pleural effusion was checked macroscopically to determine if we suspected. We made a diagnosis of chylothorax according to the criteria; the pleural fluid triglycerides (TG) $>110 \mathrm{mg} / \mathrm{dL}$, the ratio of pleural fluid TG to serum TG $>1$ and/or we made a confirmation of chylomicrons in the pleural drainage when the value of pleural fluid TG $50-110 \mathrm{mg} / \mathrm{dL}$ [11]. The duration of chylothorax was defined as days from the diagnosis of chylothorax to removal of the chest tube placed for the treatment of chylothorax.

\section{Management of chylothorax}

Generally, postoperative chylothorax is managed either conservatively or surgically. The protocol followed in our hospital and in this study involves the application of a nutritional approach first, with patients receiving total parenteral nutrition. They are started on octreotide ( $300 \mu \mathrm{g} /$ day) by continuous subcutaneous infusion and/or etilefrine $(120 \mathrm{mg} /$ day $)$ by intravenous injection concurrently. If there is progressive resolution of the chylous pleural effusion with this treatment, and the effluent is approximately less than $50-100 \mathrm{~mL} /$ day, we perform pleurodesis with OK-432. After that, the patient made satisfactory progress and resumed oral food intake. If the effluent keep approximately less than 50-100 mL/day after the oral food intake started, the thoracotomy tube was removed. If conservative treatment fails (ex. in the presence of excessive ( $>400-500 \mathrm{~mL} /$ day) chest drain output), we then consider more invasive treatment such as lymphangiography, thoracic duct embolization, or thoracic duct ligation.

\section{Statistical analysis}

All analyses were performed using the Statistical Package for the Social Sciences (SPSS) software version 19.0J for Windows (SPSS Inc., Chicago, IL). Pearson's Chi-squared test, Fisher's exact test, or the Mann-Whitney $U$ test was used for intergroup comparisons, as appropriate. Statistical significance was set at $p<0.05$.

\section{Results}

\section{Outcomes of treatment for postoperative chylothorax} (Fig. 1)

Of the 371 patients who underwent surgery for esophageal cancer, 19 patients $(5.1 \%)$ developed postoperative chylothorax, for which preservation $(n=5)$ or resection 
Fig. 1 Outcomes of treatment for postoperative chylothorax

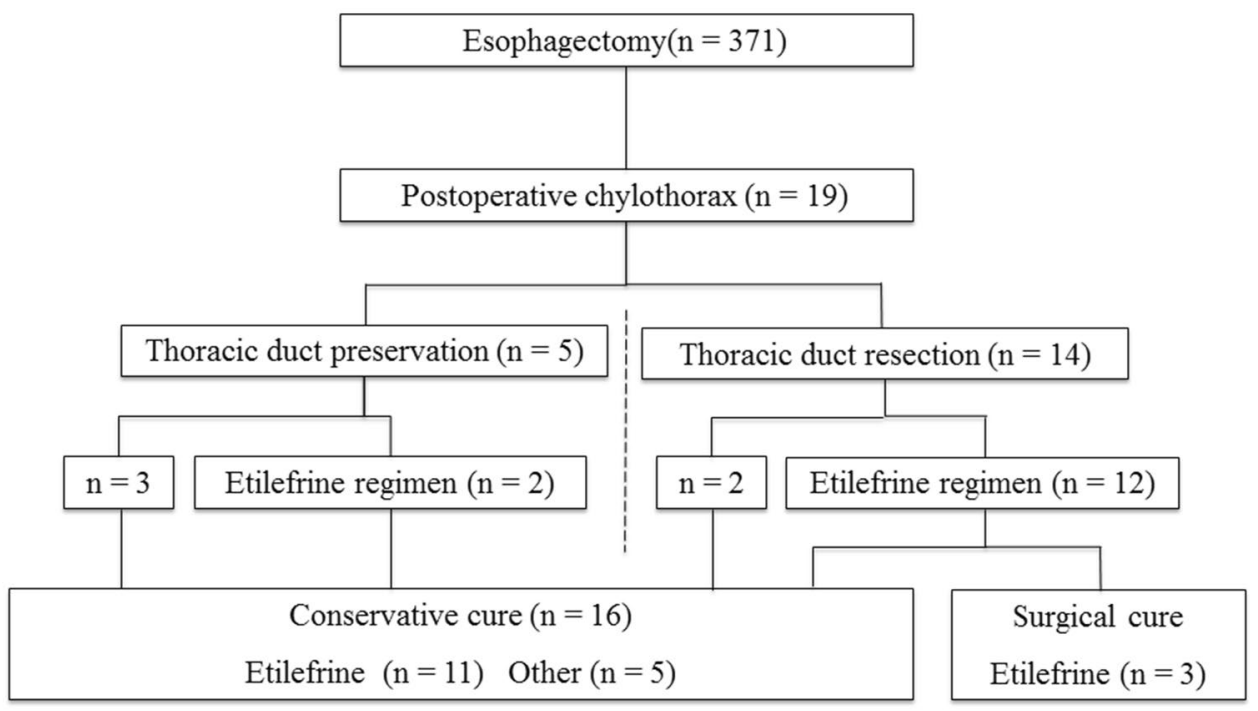

( $n=14$ ) of the thoracic duct was performed. Cure was achieved with conservative treatment in all 5 patients who had undergone thoracic duct preservation. The treatment results of 5 patients with thoracic duct preservation were two patients received etilefrine and octreotide regimen, another two patients received only nutrition approach and one patient started on octreotide only. In contrast, additional surgical treatment (thoracic duct ligation) was performed in 3 of the 14 patients who had undergone thoracic duct resection (TDR) because conservative treatment was insufficient to achieve cure. Thus, conservative treatment achieved cure in 16 patients among 19 patients with postoperative chylothorax.

\section{Effectiveness of etilefrine treatment for postoperative chylothorax}

Table 1 shows the background characteristics and surgical findings of 16 patients in whom cure was achieved after conservative treatment with $(n=11)$ and without $(n=5)$ adjuvant etilefrine treatment (see Fig. 1). Among patient background characteristics and intraoperative findings, no significant difference was found between age, sex, body mass index, clinical stage, tumor localization, extent of lymph node dissection, operative approach, resection/ preservation of the thoracic duct, organ reconstruction, duration of the operation, or blood loss. The duration of chylothorax tended to be longer in the no-etilefrine group than in the etilefrine group, but no significant difference between the two groups (27.8 vs. 11.6 days, respectively; $p=0.078$ ).

\section{Effectiveness of etilefrine treatment for postoperative chylothorax after thoracic duct resection}

Etilefrine was used in 12 of 14 patients with post-TDR chylothorax. Among these 12 patients, 3 required surgical treatment and the remaining 9 patients were cured with conservative treatment. The background characteristics of patients had no significant differences between the groups. The duration of chylothorax was shorter in the conservative treatment group than in the surgical treatment group, but no significant difference between the two groups (11.9 vs. 36.3 days, respectively; $p=0.052$ ) (the data not shown).

Table 2 shows detailed information for the 12 patients who developed chylothorax after esophagectomy with TDR. With the use of etilefrine as adjuvant therapy, cure was achieved in 9 patients (75\%) without surgical intervention.

\section{Discussion}

In this study, we have shown the effectiveness of etilefrine used in combination with conventional octreotide administration, pleurodesis, and nutritional therapy for the treatment of postoperative chylothorax following esophagectomy. Our findings suggest that when used concurrently with conventional treatments, etilefrine facilitates early chest tube removal. In addition, post-TDR chylothorax, which frequently requires surgical treatment because of the general less effectiveness of conservative treatments showed some favorable response to etilefrine treatment.

As reported previously, postoperative chylothorax is a relatively rare complication and is treated conventionally 
Table 1 Clinicopathological characteristics of the 16 patients in whom conservative cure of chylothorax was achieved

\begin{tabular}{|c|c|c|c|}
\hline & Etilefrine regimen $(n=11)$ & Other $(n=5)$ & $p$ value \\
\hline Age: median (range) & $62.2(42-76)$ & $63.6(56-74)$ & 0.910 \\
\hline Sex & & & 0.513 \\
\hline Male & 7 & 4 & \\
\hline Female & 4 & 1 & \\
\hline Body mass index $\left(\mathrm{kg} / \mathrm{m}^{2}\right)$ & $20.1(14.7-26.0)$ & $21.7(17.4-26.3)$ & 0.396 \\
\hline ASA & & & 0.785 \\
\hline 1 & 2 & 1 & \\
\hline 2 & 8 & 4 & \\
\hline $3-$ & 1 & 0 & \\
\hline cStage (7th) & & & 0.451 \\
\hline I (IA, IB) & 4 & 2 & \\
\hline II (IIA, IIB) & 1 & 2 & \\
\hline III (IIIA, IIIB) & 5 & 0 & \\
\hline IVA & 1 & 1 & \\
\hline Tumor localization & & & 0.466 \\
\hline Ut & 2 & 0 & \\
\hline Mt & 5 & 4 & \\
\hline $\mathrm{Lt}$ & 2 & 0 & \\
\hline $\mathrm{Ae}$ & 0 & 0 & \\
\hline EGJ & 2 & 1 & \\
\hline Lymphadenectomy & & & 0.513 \\
\hline D2 & 4 & 1 & \\
\hline D3 & 7 & 4 & \\
\hline Operative approach (thoracic) & & & 0.106 \\
\hline Open & 3 & 4 & \\
\hline VATS & 8 & 1 & \\
\hline Operative approach (abdominal) & & & 0.210 \\
\hline Open & 3 & 3 & \\
\hline HALS & 8 & 2 & \\
\hline Thoracic duct & & & 0.245 \\
\hline Preservation & 2 & $\underline{3}$ & \\
\hline Resection & 9 & 2 & \\
\hline Reconstruction organ & & & 0.839 \\
\hline Gastric tube & 6 & 3 & \\
\hline Ileocolon & 5 & 2 & \\
\hline Duration of operation (min) & $541(358-702)$ & $495(350-631)$ & 0.282 \\
\hline Amount of blood loss (mL) & $496(80-1413)$ & $689(285-1068)$ & 0.157 \\
\hline Duration of chylothorax (days) & $11.6(2-31)$ & $27.8(6-74)$ & 0.078 \\
\hline
\end{tabular}

All figures followed by parentheses indicate a range unless otherwise stated with nutritional therapy, drug therapy with octreotide, pleurodesis, and thoracic duct ligation. The use of etilefrine in chylothorax was reported for the first time by Guillem et al. [5]. Etilefrine has both $\alpha$-adrenergic and $\beta$-adrenergic effects and is commonly used to treat conditions such as orthostatic hypotension and priapism. Guillem et al. explained that through its sympathomimetic effect, etilefrine induces contraction of the smooth muscles of the thoracic duct or main lymphatic duct, leading to a narrowed lumen, thereby decreasing chyle output. Furthermore, etilefrine is relatively safe because it rarely causes side effects such as headache, tachycardia, hypertension, and anxiety when used in proper dose. Therefore, we incorporated an etilefrine regimen for treating postoperative chylothorax into the protocol used in our hospital. As a result, we often can perform chest tube removal much earlier than we did before the incorporation of etilefrine.

Besides the present study, there have been hardly any reports showing the effectiveness of etilefrine in cases of chylothorax after esophagectomy with TDR [12]. In surgery 


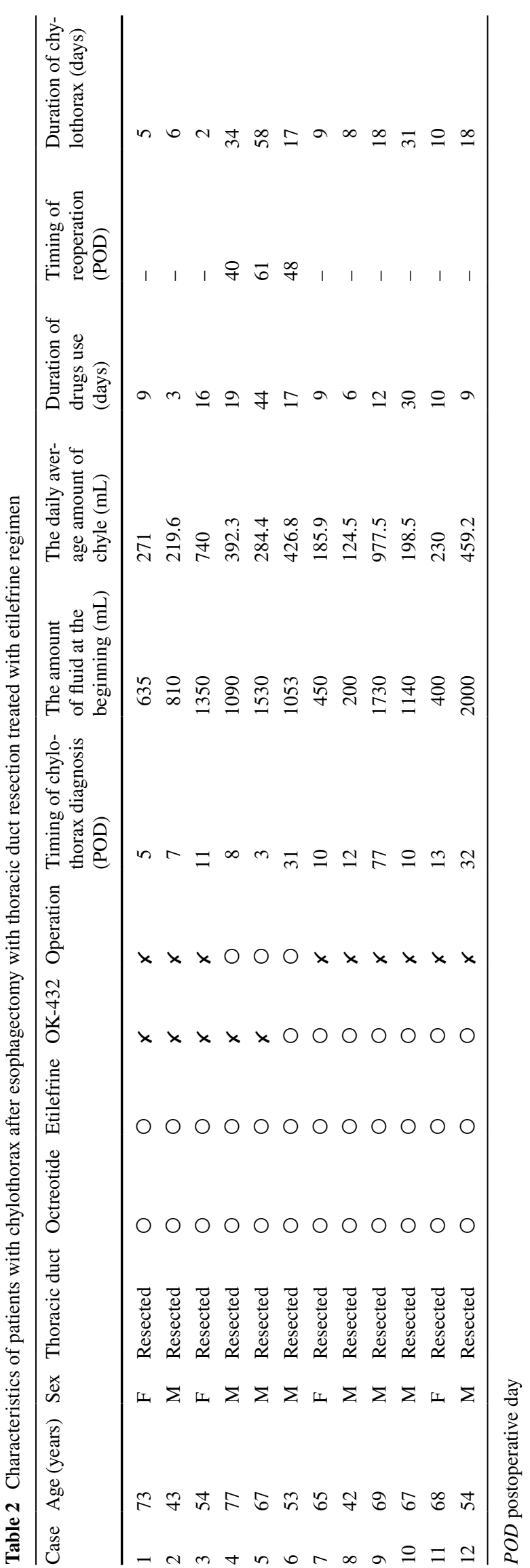

for esophageal cancer, the thoracic duct is resected to ensure thorough removal of the lymph nodes around the thoracic duct, and the oncological effectiveness of TDR has been demonstrated $[13,14]$. In performing TDR, we doubleclip the thoracic duct above the diaphragm in patients with cStage II or more advanced esophageal cancer. Post-TDR chylothorax is mainly caused by major leakage from or near the ligation site and is difficult to treat conservatively. Conservative treatment alone is ordinally not sufficient to treat post-TDR chylothorax. Ojima et al. reported the effectiveness of etilefrine therapy in patients with preserved thoracic duct but not in those with post-TDR chylothorax [8]. In previous studies, conservative treatment (excluding thoracic duct embolization) had a success rate of $53.8 \%$ in postoperative chylothorax $[3,15-20]$ with or without TDR. In the present study, as many as $75 \%(9 / 12)$ of the patients with post-TDR chylothorax, in which conservative treatment has been reported to be ineffective, had a good outcome with the addition of etilefrine regimen. In other words, our findings suggest the effectiveness of etilefrine as a novel treatment for post-TDR chylothorax, which is conventionally considered intractable. The present study also shows that it took a relatively long time to achieve cure in surgically treated group because of the preceding conservative treatment. Therefore, when conservative treatment does not reduce chyle output in patients with post-TDR chylothorax, surgery should be considered as soon as possible to achieve cure in the early stage of the disease and to reduce patient burden. We think that the timing of reoperation is about 3-4 weeks after the conservative treatment was started.

The major limitations of our study were its single-center retrospective design and the small number of patients examined. Accumulation of cases would allow more precise analysis, which might further demonstrate the effectiveness of this treatment. A multicenter study with a larger number of cases is warranted.

\section{Conclusion}

The findings of this study suggest the effectiveness of etilefrine in patients with chylothorax following esophagectomy. The drug was effective even in post-TDR chylothorax, an often intractable condition that is difficult to treat conservatively. However, when the effectiveness of etilefrine regimen is unexpectedly poor, it is important to switch from drug therapy to surgical treatment in the early stage of this complication.

Author contributions $\mathrm{YO}$ and $\mathrm{MU}$ contributed equally to this work; YO and MU designed the study, wrote the manuscript, revised it critically for important intellectual content, and gave final approval for the content; YO, MU, TI, and HU created study materials or recruited patients. 


\section{Compliance with ethical standards}

Ethical Statement All the patients of the Toranomon hospital provided written informed consent for surgery and for the possibility of their specimens to be used in future medical studies as long as their privacy was protected. The present study was also conducted in accordance with the Declaration of Helsinki (1964) and later versions and Good Clinical Practice guidelines and with the approval of the Institutional Review Boards of Toranomon hospital.

\section{Conflict of interest None declared.}

Funding None declared.

Open Access This article is distributed under the terms of the Creative Commons Attribution 4.0 International License (http://creativecommons.org/licenses/by/4.0/), which permits unrestricted use, distribution, and reproduction in any medium, provided you give appropriate credit to the original author(s) and the source, provide a link to the Creative Commons license, and indicate if changes were made.

\section{References}

1. Merrigan BA, Winter DC, O’Sullivan GC. Chylothorax. Br J Surg. 1997;84:15-20.

2. Hölscher AH, Vallböhmer D, Brabender J. The prevention and management of perioperative complications. Best Pract Res Clin Gastroenterol. 2006;20:907-23.

3. Bender B, Murthy V, Chamberlain RS. The changing management of chylothorax in the modern era. Eur J Cardiothorac Surg. 2016;249:18-24.

4. Al-Busafi SA, Ghali P, Deschênes M, et al. Chylous ascites: evaluation and management. ISRN Hepatol. 2014. doi:10.1155/2014/240473.

5. Guillem P, Billeret V, Lecomte Houcke M, et al. Successful management of post esophagectomy chylothorax/chyloperitoneum by etilefrine. Dis Esophagus. 1999;12:155-6.

6. Guillem P, Papachristos I, Peillon C, et al. Etilefrine use in the management of post-operative chyle leaks in thoracic surgery. Interact Cardiovasc Thorac Surg. 2004;3:156-60.

7. Hata T, Kawanishi K, Nagai K, et al. Successful treatment of postoperative chylothorax by etilefrine after esophageal carcinoma resection. Jpn J Gastroenterol Surg. 2013;46:79-84 (in Japanese with English abstract).

8. Ojima T, Nakamori M, Nakamura M, et al. A case of chylothorax appeared after surgery for esophageal cancer cured by administration of octreotide/etilefrine and injection of OK-432 into the pleural cavity. J Jpn Surg Assoc. 2014;75:1547-50 (in Japanese with English abstract).

9. Sobin LH, Gospodarowicz MK, Wittekind C, editors. International union against cancer. Oesophagus including oesophagogastric junction. 'TNM classification of malignant tumours'. West Sussex: Wiley-Blackwell; 2009. p. 66-72.

10. Dindo D, Demartines N, Clavien PA. Classification of surgical complications: a new proposal with evaluation in a cohort of 6336 patients and results of a survey. Ann Surg. 2004;240:205-13.

11. Staats BA, Ellefson RD, Budahn LL, et al. The lipoprotein profile of chylous and nonchylous pleural effusions. Mayo Clin Proc. 1980;55:700-4.

12. Ohkura $\mathrm{Y}$, Ueno $M$, Iizuka $\mathrm{T}$, et al. New combined medical treatment with etilefrine and octreotide for chylothorax after esophagectomy: a case report and review of the literature. Medicine (Baltimore). 2015;94(49):e2214.

13. Udagawa H, Ueno M, Shinohara H, et al. Should lymph nodes along the thoracic duct be dissected routinely in radical esophagectomy? Esophagus. 2014;11:204-10.

14. Matsuda S, Takeuchi H, Kawakubo H, et al. Clinical outcome of transthoracic esophagectomy with thoracic duct resection: number of dissected lymph node and distribution of lymph node metastasis around the thoracic duct. Medicine (Baltimore). 2016;95(24):e3839.

15. Bolger C, Walsh TN, Tanner WA, et al. Chylothorax after oesophagectomy. Br J Surg. 1991;78:587-8.

16. Marts BC, Naunheim KS, Fiore AC, et al. Conservative versus surgical management of chylothorax. Am J Surg. 1992;164:534-5.

17. Cerfolio RJ, Allen MS, Deschamps C, et al. Postoperative chylothorax. J Thorac Cardiovasc Surg. 1996;112:1361-5.

18. Dugue L, Sauvanet A, Farges O, et al. Output of chyle as an indicator of treatment for chylothorax complicating oesophagectomy. Br J Surg. 1998;85:1147-9.

19. Merigliano S, Molena D, Ruol A, et al. Chylothorax complicating esophagectomy for cancer: a plea for early thoracic duct ligation. J Thorac Cardiovasc Surg. 2000;119:453-7.

20. Paul S, Altorki NK, Port JL, et al. Surgical management of chylothorax. Thorac Cardiovasc Surg. 2009;57:226-68. 